\title{
Analysis of the Vegetation in the Terrain of Closed Industrial Waste Dump in Siechnice (Lower Silesia)
}

\author{
Łukasz Winkler ${ }^{1}$, Agnieszka Stojanowska', Justyna Rybak' \\ 1 Department of Environmental Engineering, Wroclaw University of Technology, Wybrzeże Wyspiańskiego 27, \\ 50-370 Wrocław, Poland \\ * Corresponding author's e-mail: agnieszka.stojanowska@pwr.edu.pl
}

\begin{abstract}
In this paper, the analysis of the vegetation growing on the waste dump Siechnice was carried out. On the basis of phytosociological relevès, the plant species were determined. It was shown that vegetation identified on the waste dump is similar to the plants growing around this area. What is more, ecological succession of Urticaceae was observed, which proves succession of plants preferring alkaline soils. In addition, the ecotoxicological tests did not show the contamination impact of soil samples. We recorded only a slight inhibition of growth of A. sativa (in the shoot length in lower part of dump).
\end{abstract}

Keywords: waste dump, spontaneous overgrowing, succession, heavy metals, apophytes

\section{INTRODUCTION}

Soil, as one of the most important natural resources, is essential for human development and life. It provides available nutrients to animals and plants, filtrates water and it can effectively remove some types of impurities or kill disease agents. Rapid development of industry is, obviously, very important for human beings but it can be also dangerous for the environment, especially for soil as it is the outermost layer of the Earth's crust. Soil degradation is a great problem nowadays which leads to a decline in the soil condition. Degraded soil can be easily transformed into devastated one then it ceases to be useful for human purposes. That is why, it is very important to focus on the degraded areas and try to reclaim them. The spontaneous overgrowing process in the terrain of closed industrial waste dump is a good way to observe changes that are taking place with time.

The studied dump is the abandoned smelter which previously produced chrome steel and later - noble and semi-noble ferroalloys. The place where the slag and metallurgical ashes from the inactive ferro-chromium smelter are stored is now a potential threat for residents through dusting and might be also dangerous for nearby aquifers, responsible for supplying water to the city of Wrocław [Gonada-Soroczyńska and Roman, 2000]. Spontaneous overgrowing of the waste dump is characterized by a change in the composition of the vegetation that overgrows it. The Siechnice waste dump is already fully overgrown, so it is impossible to observe overgrowing in a greater extent or isolate pioneer plant species. However, it is possible to show a gradual exchange of species for better adaptation and general impoverishment of flora by reducing biodiversity. New species present on the waste dump can be applied in the reclamation process of similar industrial areas.

Few years ago, the Siechnice waste dump was selected by the Main Inspectorate for Environmental Protection for liquidation as it posed a serious threat to the environment. Work is still underway to completely eliminate this waste dump. All metallurgical plants lead to the appearance of waste dumps on which slags and ashes are stored. These wastes contain many heavy metals, for example $\mathrm{Fe}, \mathrm{Pb}, \mathrm{Zn}, \mathrm{Cd}, \mathrm{Cr}$. Following compounds, depending on the $\mathrm{pH}$ of the soil, can occur as 
immobilized or mobile. What is more, pieces of ferrochromium, varying in their size, can occur in this waste dump.

Additionally, in order to check toxicity of the soil samples ecotoxicological tests were applied with Avena sativa L. (Poaceae).This species is commonly used in such tests because of its high growth rate and sensitivity to toxic compounds, which results in noticeable differences in the length of the stems. The roots of $A$. sativa are able to absorb nutrients, such as macroelements (nitrogen, magnesium or calcium) and micronutrients (chromium, iron), which may affect the growth.

The main aim of presented work was to analyze the vegetation composition on the waste dump and assess the possible toxicity of the soil. This research was supposed to show the variability of vegetation that grows on the waste dump, the progress of ecological succession of species and changes in the composition of vegetation that overgrows it in order to select suitable plants for reclamation of industrial, contaminated with heavy metals dumps.

\section{STUDY AREA AND METHODS}

\section{Study area}

The smelter "Siechnice" was situated in Siechnice, Lower Silesian Voivodship. In 1952, it started producing chrome steel and a few years later - noble and semi-noble ferroalloys. In 1989, the Ministry of Industry ordered the closure of the smelter as it was harmful to the environment and it could not be modernized. The postproduction ashes were stored next to the inactive smelter which was very dangerous to the environment because of high concentration of heavy metals [Biłyk and Kowal, 1993]. Heavy metals ions are one of the most common pollutants in waste dump. Their bioavailability and behavior are influenced by the desorption/adsorption and dissolution/precipitation processes between two phases: liquid and solid [Alloway, 1995].

The waste dump in Siechnice is almost 30 meters high and its volume reaches 1.9 billion $\mathrm{m}^{3}$.

The negative impact of the waste dump was reduced thanks to the use of simple reclamation actions, which quickly solved the problems that were affecting residents, i.e. dusting coming from the waste dump. In addition, the plants growing on the flat top of the waste dump slowed down the process of infiltration and transfer of substances to lower areas of the waste dump by collecting water from precipitation. However, it should be underlined that the waste dump was left without plant cover for many years, which certainly caused the accumulation of toxic compounds in this area [Roszak, 1991].

\section{METHODS}

In the paper, the Braun-Blanquet method was used for studies. It involves the determination of areas with a homogeneous plant community called the "phytosociological relevè". Four phytosociological relevès were done, where plant species were determined and their percentage in the particular relevè was calculated. One phytosociological relevè corresponded to a surface area of $25 \mathrm{~m}^{2}$, which translated into $100 \mathrm{~m}^{2}$ in total of analyzed terrain. The percentage of plant species growing on the waste dump was calculated. Taking into consideration the fact that flowering, which is the best time to make species identification, is different for individual species, the research on the waste dump in Siechnice was carried out twice (in June and in October in 2013). Additionally, classification was carried out due to the way in which plants survive the unfavorable season of the year. This analysis of flora was based on the Raunkiær classification [Raunkiær, 1934] in which five groups are distinguished: chamaephytes, hemicryptophytes, phanerophytes, cryptophytes and therophtes [Szweykowska and Szweykowski, 2003].

The acidity, humidity and trophism of the substrate (soil), were determined according to "Ekologiczne liczby wskaźnikowe roślin naczyniowych Polski" [Zarzycki and Szafer, 2002]. The assignment of plants to appropriate phytosociological classes was established by "Przewodnik do oznaczania zbiorowisk roślinnych Polski" [Matuszkiewicz, 2012] and the plants were recognized using "Klucz do oznaczania roślin naczyniowych Polski Niżowej" [Rutkowski, 2011] and "Atlas roślin łąkowych i pastwiskowych" by Rutkowska [Rutkowska, 1984].

The soil samples were collected on waste dump in Siechnice, in 2013. The samples were taken from three different parts of the waste dump (top, middle, lower part). The samples were prepared in the following concentrations: $100 \%, 75 \%, 50 \%$ and $25 \%$ with reference soil. 
At the beginning of the experiment seeds of A. sativa were placed on the cotton pad moistened with distilled water and after 48 hours they were introduced in the studied soil $(5$ seeds per sample in 5 replicates).

\section{RESULTS AND DISCUSSION}

In order to obtain better results, the research on the waste dump in Siechnice was carried out twice in the same year. Table 1 presents the species recorded in the phytosociological relevès in terms of geo-historical groups $(\mathrm{P})$, life -forms according to Raunkiaer (G). Abbreviations for ecological indicators were as follows: humidity $(\mathrm{H})$, trophism (T), acidity (A). In this table, vegetation is also assigned to phytosociological classes $(\mathrm{K})$.

In the studied area, apophytes, species of plants of local origin that have adapted to life on human-made habitats, were the most common and accounted for $67 \%$ of the plants. The participation of species belonging to this group is similar to that in previous years (apophytes $-61 \%$, archeophytes $-7 \%$, kenophytes $-27 \%$ [KoszelnikLeszek et al., 2013]). The results and percentage of particulars groups are presented in Figure 1.

The participation of plant families is shown in Figure 2. The most numerous group are the species belonging to Asteraceae (32\%) and Poaceae $(20 \%)$. Asteraceae are known for growing on the moderately alkaline and alkaline ground. This $\mathrm{pH}$ level was recorded in soil and slag under the soil in this location. Poaceae probably occur in this place due to their low soil requirements and fact that earlier they were indroduced by human. Plants from this family are often used

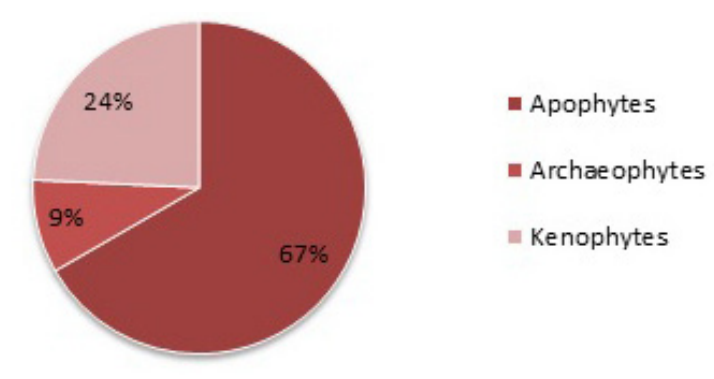

Figure 1. The share of geo-historical groups

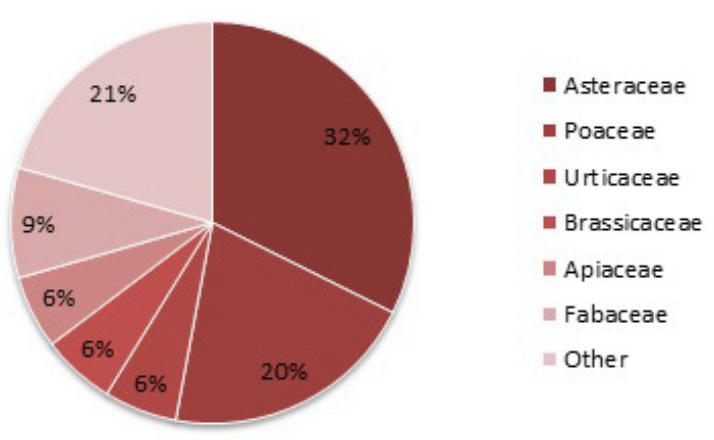

Figure 2. The share of individual families

in the reclamation process because they quickly overgrow the land and thus reduce dusting. In addition, they consolidate the substrate, making it difficult to infiltrate impurities.

Soil acidity indicator was measured in 2009 and it was published in 2013 [Koszelnik-Leszek, 2013]. Figure 3 and 4 show comparison of species preferences depending on the $\mathrm{pH}$ of the soil.

Some plant species prefer the soil of a narrow $\mathrm{pH}$ range, others have a high tolerance for soil $\mathrm{pH}$.

In four years, the growth of plants favoring medium or strongly alkaline soils has increased, which indicates the dispersion of alkaline species
2009

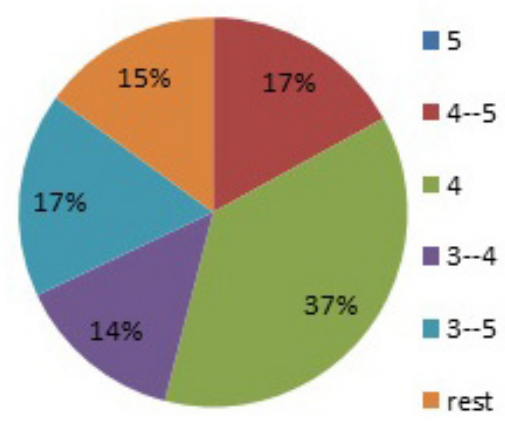

Figure 3. Acidity index of soils, Siechnice 2009

\section{3}

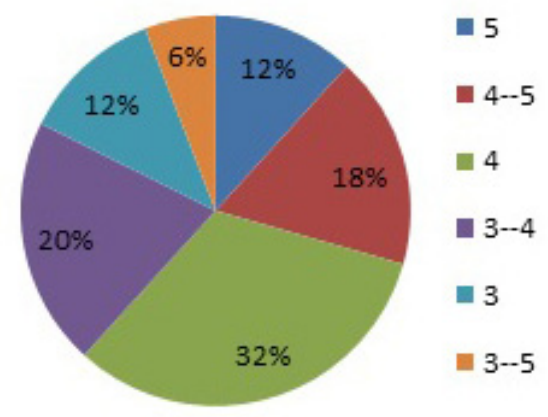

Figure 4. Acidity index of soils, Siechnice 2013

Legend: 3 - Species of medium-acid soil $(5<\mathrm{pH}<6), 4$ - Species of neutral $\mathrm{pH}$ of soil $(6<\mathrm{pH}<7), 5$ - Species of alkaline soil $(\mathrm{pH}>7)$ 
in the area of waste dump. This is probably due to the fact that the slag stored on the waste dump was characterized by strongly alkaline $\mathrm{pH}$ values. It was caused by the liming process used in the technological system, owing to which the ferrochrome production process ran more efficiently. What is more, ecological succession of Urticaceae was observed, the presence of Urtica urens $L$ (annual nettle) was recorded, which is

Table 1. The fauna composition of the Siechnice waste dump

\begin{tabular}{|c|c|c|c|c|c|c|c|c|c|}
\hline No & Species & Order & Family & P & G & $\mathrm{H}$ & $\mathrm{T}$ & A & $\mathrm{K}$ \\
\hline 1 & Artemisia vulgaris $\mathrm{L}$. & Asterales & Asteraceae & Ap & $\mathrm{Ch}$ & 3 & 4 & $3-4$ & $A$ \\
\hline 2 & Sisymbrium loeseli L. & Brassicales & Brassicaceae & $\mathrm{Kn}$ & $\mathrm{H}$ & 2 & 3 & $4-5$ & $\mathrm{Sm}$ \\
\hline 3 & Carduus acanthoides L. & Asterales & Asteraceae & Ap & $\mathrm{H}$ & 2 & 3 & 4 & O-A \\
\hline 4 & Holcus lanatus L. & Poales & Poaceae & Ap & $\mathrm{H}$ & 4 & $3-4$ & $3-4$ & $M-A$ \\
\hline 5 & Erigeron annuus L. & Asterales & Asteraceae & $\mathrm{Kn}$ & $\mathrm{H}, \mathrm{T}$ & 3 & 3 & $3-4$ & $\mathrm{Sm}$ \\
\hline 6 & Arctium lappa L. & Asterales & Asteraceae & Ap & $\mathrm{H}$ & 3 & 4 & $3-4$ & A \\
\hline 7 & Urtica dioica L. & Rosales & Urticaceae & Ap & $\mathrm{H}$ & $3-4$ & $4-5$ & 4 & $A$ \\
\hline 8 & Conium maculatum $\mathrm{L}$. & Apiales & Apiaceae & $\mathrm{Ar}$ & $\mathrm{H}$ & 3 & $3-4$ & $4-5$ & A \\
\hline 9 & Poa trivialis $\mathrm{L}$. & Poales & Poaceae & Ap & $\mathrm{H}$ & 3 & $4-5$ & $4-5$ & $M-A$ \\
\hline 10 & Sambucus nigra L. & Dipsacales & Adoxaceae & Ap & $\mathrm{F}$ & 3 & 4 & 5 & - \\
\hline 11 & Echinops sphaerocephalus L. & Asterales & Asteraceae & $\mathrm{Kn}$ & $\mathrm{H}$ & 3 & $4-5$ & 4 & $\mathrm{M}-\mathrm{A}$ \\
\hline 12 & Arrhenatherum elatius & Poales & Poaceae & Ap & $\mathrm{H}$ & 3 & 4 & 4 & M-A \\
\hline 13 & Galium aparine L. & Gentianales & Rubiaceae & Ap & $\mathrm{T}, \mathrm{H}$ & $4-3$ & $4-5$ & 4 & A \\
\hline 14 & Fumaria officinalis L. & Ranunculales & Papaveraceae & Ap & $\mathrm{H}$ & $2-3$ & 3 & 5 & A \\
\hline 15 & Conyza canadensis L. & Asterales & Asteraceae & $\mathrm{Kn}$ & $\mathrm{H}$ & 2 & $2-3$ & 4 & E-B \\
\hline 16 & Convolvulus arvensis L. & Asterales & Convolvulaceae & Ap & $\mathrm{H}$ & $2-3$ & 3 & $4-5$ & A-R \\
\hline 17 & Cirsium vulgare & Asterales & Asteraceae & $\mathrm{Kn}$ & $\mathrm{H}$ & 3 & $4-3$ & $3-4$ & $A$ \\
\hline 18 & Carex ovalis & Poales & Cyperaceae & Ap & $\mathrm{H}$ & 5 & $3-4$ & $3-4$ & - \\
\hline 19 & $\begin{array}{l}\text { Calamagrostis } \\
\text { canescens Weber Roth }\end{array}$ & Poales & Poaceae & Ap & $\mathrm{H}$ & $3-4$ & 3 & 3 & $E$ \\
\hline 20 & Bromus inermis Leyss & Poales & Poaceae & Ap & $\mathrm{H}$ & 3 & 4 & 4 & $\mathrm{M}-\mathrm{A}$ \\
\hline 21 & Artemisia absinthium L. & Asterales & Asteraceae & $\mathrm{Ar}$ & $\mathrm{Ch}$ & $2-3$ & 3 & $3-4$ & A \\
\hline 22 & Amaranthus retroflexus & Caryophyllales & Amaranthaceae & $\mathrm{Kn}$ & $\mathrm{T}$ & $4-5$ & $3-4$ & $4-5$ & - \\
\hline 23 & Lotus corniculatus L. & Fabales & Fabaceae & $\mathrm{Kn}$ & $\mathrm{H}$ & 4 & $2-3$ & 3 & $\mathrm{O}$ \\
\hline 24 & Melilotus albus & Fabales & Fabaceae & $\mathrm{Kn}$ & $\mathrm{H}$ & $1-2$ & $2-3$ & 3 & E-M \\
\hline 25 & Pimpinella major & Apiales & Apiaceae & Ap & $\mathrm{H}$ & 3 & 4 & 4 & $\mathrm{M}-\mathrm{A}$ \\
\hline 26 & Poa pratensis L. & Poales & Poaceae & Ap & $\mathrm{H}$ & $3-4$ & 4 & $4-5$ & $\mathrm{M}-\mathrm{A}$ \\
\hline 27 & Verbascum phlomoides L. & Lamiales & Scrophulariaceae & Ap & $\mathrm{H}$ & 3 & $3-4$ & $4-5$ & A \\
\hline 28 & Trifolium arvense L. & Fabales & Fabaceae & Ap & $\mathrm{H}$ & 2 & $1-2$ & $4-5$ & M-A \\
\hline 29 & Thlaspi arvense & Brassicales & Brassicaceae & $\mathrm{Ar}$ & $\mathrm{H}$ & 3 & $2-3$ & 5 & $\mathrm{Sm}$ \\
\hline 30 & Tanacetum vulgare L. & Asterales & Asteraceae & Ap & $\mathrm{H}$ & $3-4$ & 4 & 4 & A \\
\hline 31 & Senecio erucifolius L. & Asterales & Asteraceae & Ap & $\mathrm{H}$ & $2-3$ & 3 & 4 & - \\
\hline 32 & Calamagrostis epigeios L. & Poales & Poaceae & Ap & $\mathrm{H}$ & 3 & 3 & 3 & $\mathrm{E}$ \\
\hline 33 & Plantago lanceolata & Lamiales & Plantaginaceae & Ap & $\mathrm{H}$ & $2-4$ & $3-4$ & 4 & $\mathrm{M}-\mathrm{A}$ \\
\hline 34 & Urtica urens L. & Rosales & Urticaceae & $\mathrm{Ar}$ & $\mathrm{T}$ & $3-4$ & $3-5$ & 5 & U-M \\
\hline
\end{tabular}

Where:

$\mathrm{P}$ - classification due to geo-historical origin: Ar - archeophytes, Ap - apophytes, Kn - kenophytes;

G - Raunkiaer system: Ch - Chamaephytes, T - Therophytes, F - Phanerophytes, H - Hemicryptophytes;

H - Humidity: 1 - very dry, 2 - dry, 3 - fresh, 4 --damp, 5 - wet, 6 - water;

T - Trophism: 1 - extremely oligotrophic, 2 - oligotrophic, 3 - mesotrophic, 4 - eutrophic, 5 - extremely fertile soil;

A - soil acidity: $1-$ strongly acidic $(<4 \mathrm{pH}), 2-$ acidic $(4<\mathrm{pH}<5), 3-$ moderately acidic $(5<\mathrm{pH}<6)$, 4 - neutral $(6<\mathrm{pH}<7), 5$ - alkaline $(\mathrm{pH}>7)$

$\mathrm{K}$ - assignment of plants to appropriate phytosociological classes: O-A - Onopordetum acanthii, E-B - Erigeronto-Bryetum, O - Arrhenatheretalia, E-M - Echio-Meliloteum, A - Artemisietea vulgaris, M-A - molinio arrhentheretea, Sm - Stellarietea mediae, E - Epilobietea angustifolii, A-R - Agropyretea intermedio-repentis, U-M - Urtico-Malvetum. 
considered an indicator species of alkaline soils [Rutkowski, 2011].

The presence of plants that favor highly acidic soils was not recorded, while an increase in the share of plants preferring medium acidic soils was found in some parts of the waste dump. It follows that a part of the waste dump loses its alkaline $\mathrm{pH}$ value, probably due to the precipitation of calcium compounds from the slag along with precipitation. The differences in the $\mathrm{pH}$ of the soil in various parts of the waste dump may derive from its structure. Figures 5 and 6 show the comparison of trophism index.

Comparing the Figures 5 and 6, no major changes were found. Slight changes can be noticed in the proportion of plants growing on extremely poor and poor soils. Most of the plants are considered as eutrophic and rich in nutrients. This soil was and still is fertile, which allowed plants to grow quickly and cover the wastelands with grasses from the beginning of the recultivation of the waste dump.

The research conducted in 2013 was compared with the research carried out in 2008 and 2009 [Koszelnik-Leszek, 2013.]. The results are presented in Table 2.

Some of the species disappeared with time. In addition, there were species that widened their range and those that appeared from other areas. The results of ecotoxicological test with $A$. sativa are shown in the Table 3.

The results show that probably the soil is not contaminated with heavy metals as only slight inhibition of growth of A. sativa was observed in
2009

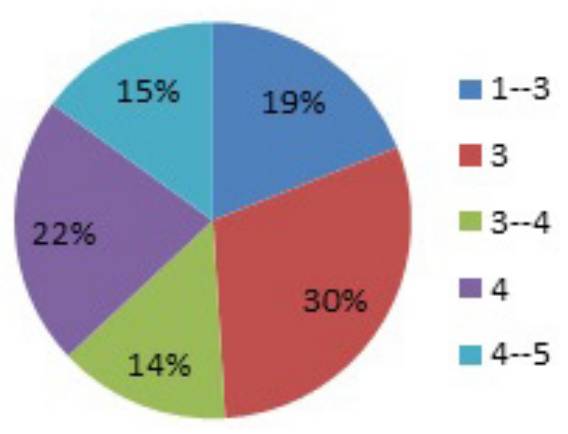

Figure 5. Trophism Index, Siechnice 2009

\section{3}

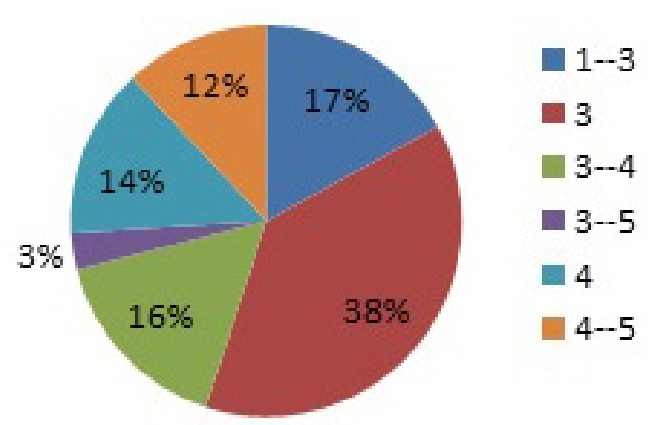

Figure 6. Trophism Index, Siechnice 2013

Legend: 1 - extremely oligotrophic, 2 - oligotrophic, 3 - mesotrophic, 4 - eutrophic, 5 - extremely fertile soil.

Table 2. Comparison of species composition

\begin{tabular}{|l|c|c|c|c|}
\hline \multicolumn{1}{|c|}{ Species } & Family & 2008 & 2009 & 2013 \\
\hline Achillea millefolium & Asteraceae & + & -- & -- \\
\hline Dactylis glomerata & Poaceae & + & + & -- \\
\hline Anthemis arvenis & Asteraceae & + & -- & -- \\
\hline Agropyron repens & Poaceae & + & -- & -- \\
\hline $\begin{array}{l}\text { Phalaris } \\
\text { arundinacea }\end{array}$ & Poaceae & + & -- & -- \\
\hline Erigeron canadensis & Asteraceae & + & -- & -- \\
\hline $\begin{array}{l}\text { Calamagrostis } \\
\text { canescens }\end{array}$ & Poaceae & decrease in number of \\
\hline $\begin{array}{l}\text { Carduus } \\
\text { acanthoides }\end{array}$ & Asteraceae & -- & -- & + \\
\hline Holcus lanatus & Poaceae & -- & -- & + \\
\hline Poa trivialis & Poaceae & -- & -- & + \\
\hline Poa pratensis & Poaceae & -- & -- & + \\
\hline Urtica dioica & Urticaceae & \multicolumn{2}{|c|}{ increase in number } \\
\hline
\end{tabular}

Table 3. Results of shoot and root length in A. sativa

\begin{tabular}{|c|c|c|}
\hline Share & Shoot length & Root length \\
\hline \multicolumn{3}{|c|}{ Top } \\
\hline $100 \%$ & 3.48 & 9.46 \\
\hline $75 \%$ & 3.59 & 5.41 \\
\hline $50 \%$ & 3.13 & 4.86 \\
\hline $25 \%$ & 3.15 & 4.19 \\
\hline \multicolumn{3}{|c|}{ Middle } \\
\hline $100 \%$ & 3.34 & 6.61 \\
\hline $75 \%$ & 3.50 & 4.65 \\
\hline $50 \%$ & 3.08 & 4.96 \\
\hline $25 \%$ & 3.53 & 6.61 \\
\hline \multicolumn{3}{|c|}{ Bottom } \\
\hline $100 \%$ & 2.91 & 5.83 \\
\hline $75 \%$ & 2.99 & 6.50 \\
\hline $50 \%$ & 3.94 & 7.62 \\
\hline $25 \%$ & 3.65 & 6.32 \\
\hline Reference soil 1 & 3.19 & 6.36 \\
\hline Reference soil 2 & 3.21 & 8.00 \\
\hline
\end{tabular}


relation to the control soil (in the shoot length in lower part of dump). It was not possible to calculate LC50 as the inhibition was quite small.

\section{DISCUSSION}

When we compare our studies to previous 2008 and 2009 the disappearance of some species was noticed. These species were: Calamagrostis canescens, Achillea millefolium, Phalaris arundinacea, Dactylis glomerata, Agropyron repens, Anthemis arvenis, Erigeron canadensis. Also some new species appeared: Carduus acanthoides, Holcus lanatus, Poa trivialis, Poa pratensis, Urtica dioica.

In some parts of the studied area, the succession of alkaline plants from the Urticaceae family occurred, such as Urtica dioica (common nettle) or Urtica urens (annual nettle), for example.

The studied area is characterized by a relatively small number of species. The reason for this is an agricultural, non-diversified neighborhood, there are no areas with great diversity nearby. In Poland, there are also the waste dumps which are characterized by a very diverse flora. They fit into the landscape because of the closeness to the landscape areas. An example of such an area can be the nature reserve "Wyspy Zawadowskie", which is located near the ash storage depot from the "Siekierki" power plant. Another example is the soda dump created as a result of the activity of glasswork called "Szczakowa". In this area, 257 species of plants were recorded, where apophytes make up $71 \%$. Large species diversity and the fact that $29 \%$ of plants do not belong to the native flora may suggest the participation of seed transport from residential areas, plots and their free development on these wasteland [Skubała, 2011].

The studies of the ecological succession of the landfill, created at the area of the opencast brown coal mine, conducted by Prach showed particular stages of spontaneous overgrowing [Prach and Hodacová, 2003]. At first, the annual and biennial plants appear. The next stage, which takes place after a few years, is the replacement of annual plants by native, pioneer species, especially by Tanacetum vulgare or Artemisia vulgaris. These species are very popular on the waste dump in Siechnice. Grasses such as Calamagrostis epigejos and Arrhenatherum elatius, which appear after 15-20 years of free succession, constitute a large share. Therefore, a typical process of overgrowing by species characteristic for this type of waste dumps could be recognized. However, overgrowing on the waste dump in Siechnice is not spontaneous according to the fact that this process was accelerated by introducing the plants to protect the area from dusting after smelter closure.

\section{CONCLUSIONS}

1. The vegetation identified on the waste dump is similar to the plants growing around this area, suggesting the natural succession from neighboring areas. The apofitic species are becoming increasingly popular on the waste dump.

2. Apophytes (plants of local origin that have adapted to life on human-made habitats) constituted $67 \%$ and $24 \%$ of all species were kenophytes (plant species which are not native to a geographical region).

3. The increase in the number of alkaline species was recorded. Ecological succession of Urticaceae was observed, which proves succession of plants preferring alkaline soils. A slight increase in the species preferring acidic soil was also noted, which may indicate the leaching of calcium compounds from some areas and the heterogeneous structure of the heap, affecting the permeability of chemical compounds.

4. Ecotoxicological tests did not show the contamination impact on the soil samples. On studied species of A. sativa, we recorded only slight a inhibition of growth of $A$. sativa (in the shoot length in lower part of dump). It was not possible to calculate LC50, which suggests that the waste dump does not pose a great treat to environment.

\section{Acknowledgements}

The investigations were co-financed within the framework of the order No. 0401/0056/18 with the specific subsidy granted for the Faculty of Environmental Engineering Wroclaw University of Science and Technology (W-7) by the Minister of Science and Higher Education.

\section{REFERENCES}

1. Alloway B. J. 1995. Soil processes and the behavior of metals. In: Alloway, B. J. (Ed.), Heavy metals in soils. Blackie, London, p. 1-37. 
2. Biłyk A., Kowal A. L. 1993. Assesment of chromium contamination hazard to the aquifers of Wrocław. Environmental Protection, p. 1-2 (in Polish).

3. Biłyk A., Michaś R. 1992. Transformations of chromium compounds in water treatment processes. Environmental Protection, p. 1-5 (in Polish).

4. Chmielarz U. 2013. Studies on the sequential extraction of selected metals and their mobility in industrial ashes. Ph.D. Thesis, University of Rzeszów, Rzeszów (in Polish).

5. Gonada-Soroczyńska E., Roman G. 2000. Outline of the history of the power plant in Siechnice. Typescript, Wrocław, p. 3 (in Polish).

6. Koszelnik-Leszek A., Podlaska M., Tomaszewska K. 2013. Diversity of vascular flora of waste dumps and dumping grounds in Lower Silesia. Archives of Environmental Protection, 39(2), 81-105.

7. Matuszkiewicz W. 2012. A guide for marking plant communities in Poland. PWN, Warszawa (in Polish).

8. Prach K., Hodacová D. 2003. Spoil Heaps From Brown Coal Mining: Technical Reclamation Versus Spontaneous Revegetation. Restoration
Ecology, 11(3), 385-391.

9. Raunkiær C. 1934. The life forms of plants and statistical plant geography. Oxford University Press.

10. Roszak W. 1991. Chemical composition of shallow groundwater in the Odra ice-marginal valley in the area of Wrocław . University of Wrocław, Wrocław (in Polish).

11. Rutkowska B. 1984. Atlas roślin łąkowych i pastwiskowych. PWRiL, Warszawa.

12. Rutkowski L. 2011. The Key for the Determination of Polish vascular plants in the lowlands. PWN, Warszawa (in Polish).

13. Skubała K. 2011. Metals on the example of two post-industrial spoil heaps connected with manufacturing of zinc and lead products in upper Silesia. Archives of Environmental Protection, 37, 3-22.

14. Szafer W., Zarzycki L. 1972. Vegetation of Poland. PWN, Warszawa (in Polish).

15. Szweykowska A., Szweykowski J. 2003. Botany, Morphology. PWN, Warszawa (in Polish).

16. Zarzycki K., Szafer W. 2002. Ecological indicator values of vascular plants of Poland. Institute of Botany, Polish Academy of Sciences, Kraków (in Polish). 